\title{
Evaluation of In vitro Antioxidant Potential of Aconitum napellus Linn. Root Extract
}

\author{
Karuna DS 1 , Dey $\mathrm{P}^{2}$, Kundu $\mathrm{A}^{3}$, Vishal V4, Bhakta T5* \\ ${ }^{1}$ Department of Pharmaceutics, C. L. Baid Metha College of Pharmacy, India \\ ${ }^{2}$ Department of Pharmaceutical Chemistry, C. L. Baid Metha College of Pharmacy, \\ India \\ 3Department of Pharmaceutical Technology, Jadavpur University, India \\ ${ }^{4}$ Department of Botany, Bangabasi Evening College, India \\ ${ }^{5}$ Regional Institute of Pharmaceutical Science \& Technology, Agartala, India
}

*Corresponding author: Tejendra Bhakta, Regional Institute of Pharmaceutical Science \& Technology, Agartala, Tripura (W), India, Email: tbhakta2016@gmail.com

\section{Abstract}

Objective: The primary focus of the research work is to explore the antioxidant potential of ethanolic root extract of Aconitum napellus Linn. (EEAN).

Methods: Different methods like DPPH scavenging activity, hydroxyl radical scavenging activity, and nitric oxide scavenging activity was followed to evaluate the in vitro antioxidant profile. HPTLC fingerprint investigation was executed for qualitative determination of a promising number of constituents from the ethanolic extract. OECD guideline 423 was followed for the determination of acute toxicity in Wistar rat.

Results: The total yield was found $0.948 \%$ from the ethanolic root extract. The results revealed that the ethanolic root extract of Aconitum napellus Linn. possesses good antioxidant activity in a concentration-dependent manner. According to DPPH radical scavenging assay, a concentration of $494.50 \pm 2.62 \mu \mathrm{g} / \mathrm{ml}$ of antioxidant material essential to rummage $50 \%$ of free radical. The ethanolic extract holds an $\mathrm{IC}_{50}$ value of $579.57 \pm 1.85 \mu \mathrm{g}$ and $469.56 \pm 2.16 \mu \mathrm{g}$ as determined by hydroxyl radical scavenging assay and nitric Oxide scavenging assay respectively. The plant extract possesses significant dose-dependent $(0.284 \pm 0.0018$ at $125 \mu \mathrm{g} / \mathrm{ml}$ and $0.923 \pm 0.0003$ at $500 \mu \mathrm{g} / \mathrm{ml})$ reducing capacity. HPTLC fingerprint information supports numerous fundamental pieces of evidence like isolation, purification, quality assessment and standardization. Aconitum napellus Linn. was found to be highly toxic at a dose of $2000 \mathrm{mg} / \mathrm{Kg}$ which was confirmed by the death of the rat. Therefore, the $\mathrm{LD}_{50}$ of this ethanolic root extract was estimated to be $\geq 2000 \mathrm{mg} / \mathrm{kg}$.

Conclusion: The Aconitum napellus ethanolic root extract in this study showed potential to be used as a natural antioxidant at a limited concentration. Root extracts from this plant might have potential applications in pharmaceutical and cosmeceutical formulations in the future.

Keywords: Aconitum napellus Linn.; Antioxidant study; HPTLC analysis; Acute toxicity 
Abbreviations: AHRF: Asthagiri Herbal Research Foundation; DPPH: 2,2-diphenyl-1-picrylhydrazyl; HPTLC: High-performance thin layer chromatography; OECD: The Organisation for Economic Co-operation and Development; ROS: Reactive Oxygen Species; TEAC: Trolox Equivalent Antioxidant Capacity.

\section{Introduction}

Free radical can be characterized as an atom, molecule, or ion possesses one or more unpaired valence electrons that contribute to the development of several lifethreading diseases counting aging [1]. Various endogenous (e.g. normal cellular metabolism) or may be exogenous (viz. irradiation) developments are responsible for the generation of free radical as a by-product. Free radicals can effortlessly react with reactive oxygen species (ROS) and make themselves active radical. Different activated forms of oxygen can be well-defined as ROS and they are of two distinctive types, free stimulated oxygen radicals (e.g. hydroxyl radical $\mathrm{OH}^{-}$, superoxide anion radical $\mathrm{O}_{2}{ }^{-}$) and non-free stimulated oxygen radicals (viz. singlet oxygen 102 , hydrogen peroxide $\mathrm{H}_{2} \mathrm{O}_{2}$ ). These activated ROS are responsible for approximately 10,000 oxidative hits to human cells in every second [2].

Free radicals are responsible for deteriorating various food items which result in off taste and diminished shelflife. Antioxidants can capable to reduce the deterioration of foodstuffs by neutralizing functional free radicals, hence use as a preservative [3]. To reduce the degradation, some nutritional food merchandises contain a ubiquitous amount of flavonoids, a type of polyphenols possessing strong antioxidant activity [4].

Like Trolox Equivalent Antioxidant Capacity (TEAC) assay, various methods are available to isolate and categorize most promising antioxidants by paralleling antioxidant capability of numerous compounds.

In the field of chemistry, the method oxidation can be defined as a chemical reaction by which an electron is transferred to an oxidizing agent from any substance. An antioxidant, a complement of oxidant, can able to minimize the rate of an oxidation reaction in a certain extent and prevent the oxidative damage to the cells and other biochemicals. They can also inhibit the unrestrained production and assembly of ROS, protein degradation, and DNA strand break and guarantee sound health $[5,6]$. Free radicals are highly responsible for development and progression of several diseases. In this connection, the involvement of LDL oxidation in cardiovascular disease can be produced as an example. This free radical-mediated LDL oxidation serves as a predecessor in different life- threatening diseases viz. cardiovascular disease, atherosclerosis, hypertension etc. by prompting many chemical or enzymatic pathways [7].

Any food or dietary supplements containing antioxidant can competent to minimize the free radicals induced cell damage. Plants are a rich source of various organic antioxidant chemicals and a systematic diet of antioxidants from plants is very crucial sustaining sound health [8]. A sufficient diet of antioxidant-rich food can able to slow down or inhibit certain diseases like aging. In this connection, different antioxidant rich (viz. vitamin E, resveratrol, carotene, selenium, vitamin $\mathrm{C}$ etc.) dietary supplements are marketed by many nutraceutical companies.

Mother Nature provides different ailments to prevent or cure various diseases and among them, several plants possess numbers of medicinal properties [9-12]. Traditional healers use their knowledge to cure or treat different diseases with the help of medicinal plants [1315]. Based on their ethnomedicinal properties, one can accelerate design and development of rational drugs or plant-derived physiologically active molecules after being fused with synthetic chemistry, QSAR and nanotechnology to combat various deadly diseases like diabetes and cancer [16-20].

The present objective of this research work is to find out the antioxidant potential of EEAN i.e. ethanolic root extract of Aconitum napellus Linn.

\section{Plant Introduction}

Aconitum napellus is an herbaceous perennial plant growing to 2-5 feet tall, with hairless stems and leaves. The flowers are violet in colour in mid-summer. Although the poison from this plant was used as an arrow toxin, it was first introduced in homeopathic medicine in 1805 [21]. Aconitum napellus is also known as monk's hood in English, vatsanabha in Sanskrit, bachnag in Hindi and kathvish in Bengali. It has been used to relieve stress, anxiety, fever due to typhoid, measeles etc.

But high dose for a longer period can cause swollen throat, sneezing and cough.

\section{Traditional Uses of Aconitum napellus Linn.}

This plant is used to prepare homeopathic preparation from long time [22]. The extracts obtained from Aconitum species are usually employed in the traditional Chinese and Japanese medicine as analgesics, anti-rheumatics and also for the treatment of neurological disorders [23]. It is also used as an anti-microbial agent [24]. 


\section{Phytochemical Evaluation}

From literature survey, it was proved that Aconitum napellus Linn. possesses Quercetin3-0-(6-transcaffeoyl)- $\beta$ glucopyranosyl-( $1 \rightarrow 2)$ - $\beta$-glucopyranosyl-7-0- $\alpha$ -

rhamnopyranoside and quercetin-3-sophoroside-7rhamnopyranoside [25]. Apart from this, it also possesses alkaloid, carbohydrate, glycosides, protein, flavonoid, tannin but it is devoid of terpene, gum \& mucilage and steroid.

\section{Materials and Methods}

\section{Collection of Plant}

The plant material was collected from Kulasekharam of Kanyakumari district and authorized by Prof. P. Jeyaraman Chief Botanist PARC, Chennai, India.

\section{Preparation of Plant Extracts [26]}

Air-dried roots $(1.5 \mathrm{~kg})$ were extracted by hot maceration procedure with absolute ethanol (3 L) at a temperature not exceeding $55^{\circ} \mathrm{C}$ for 4 days and filtered. This filtrate was concentrated by rotary evaporator. This concentrated material was used for next study.

\section{Source of Chemicals}

All the chemicals were of analytical reagent grade and purchased from Loba Chemie, ACROS Organics, Merck lab, S.D. Fine chemicals, Fluke.

\section{In vitro antioxidant Evaluation}

DPPH Method: Free radical scavenging assay was measured by DPPH method [27].

DPPH percentage inhibition $(\%)=$ Abs (control) - Abs (sample) / Abs (control) X 100

Hydroxyl Radical Scavenging Assay: The free radical scavenging capacity of EEAN was measured by hydroxyl radical Scavenging method [28].

Hydroxyl scavenging activity $(\%)=$ Abs (control) - Abs (sample) / Abs (control) X 100

Nitric Oxide Scavenging Assay: Nitric oxide scavenging technique was used to find out the antioxidant activity of ethanolic root extract [29].

Nitric oxide scavenging assay $(\%)=$ Abs (control) - Abs (sample) / Abs (control) X 100

Total Reducing Ability: The reducing power of the ethanolic root extract was determined by various concentrations of the ethanolic extract, phosphate buffer (2.5ml, 0.2M, pH 6.6) and potassium ferricyanide (2.5 ml,
1\%), trichloroacetic acid (10\%), ferric chloride (1\%) [30]. HPTLC Analysis: HPTLC of the EEAN sample was identified by AHRF method. The sample applicator used for the procedure was CAMAG Linomat IV. The applied sample was scanned by CAMAG TLC Scanner II.

Volume of sample loaded- $10 \mu \mathrm{l}$

Mobile phase- Diethylamine:Ethylacetate:Toluene

(10:20:70)

$\lambda$ - max: $254 \mathrm{~nm}$

Lamp: Deuterium

\section{Determination of Toxicity}

Experimental Animals: Adult male Wistar rats (150-180 g) were used for this study. Standard laboratory diet and tap water were used to feed all the animals. The care and use of the animals were strictly followed in accordance to the guidance of the Institutional Ethical Committee (constituted under the Guidelines Committee for the Purpose of Control and Supervision of Experiments on Animals, Reg. No. - 1237/P0/C/2008/CPCSEA). After one week of habituation, animals were used for the experiments. Each animal was tested only once. All efforts were made to reduce animal suffering.

Acute Oral Toxicity Study (OECD ${ }^{423}$ ): OECD guidelines 423 were followed for the oral toxicity study. It is a stepwise practice with three animals of a single sex per stage. Based on the mortality and/or morbidity of the animals a few stages may be compulsory to evaluate the toxicity of the test ingredient. This method has a benefit over other procedures because of marginal usage of animals while permitting for satisfactory data [31-33]. The technique uses well-defined doses (2000mg/kg body weight) and the outcomes permit an ingredient to be ranked and categorized according to the globally synchronized system. The concentrated EEAN extract was dissolved in distilled water for oral administration. The initial dose of the EEAN extract was $2000 \mathrm{mg} / \mathrm{kg}$ bodyweight (p.o). The dose was administered to the mice which were fasted overnight with water ad libitum and examined for signs of toxicity symptoms like change in diarrhea, convulsions, salivation, tremors, sleep, skin color and also respiratory, autonomic and CNS effects.

Statistical analysis: Results were shown as mean \pm S.D. for each group (where, number of each in-vitro antioxidant experiment, $n=3$; the number of experimental animals, $\mathrm{n}=6$ ). SPSS 9.0 for Windows (Chicago, IL, USA) software was used for statistical analysis. For multiple comparisons, one-way analysis of variance (ANOVA) was performed. In cases where ANOVA indicated noteworthy differences, Tukey test was performed. $\mathrm{P}<0.01$ was considered to be statistically important. 


\section{Results}

\section{Percentage Yield Study}

The percentage yield of the EEAN was found to be $0.948 \%$.

\section{DPPH Radical Scavenging Assay}

Figure 1 shows the antiradical activity of EEAN. The scavenging activity was increased with the increasing concentrations $(25-800 \mu \mathrm{g})$. $\mathrm{IC}_{50}$ value (the amount of antioxidant material required to scavenge $50 \%$ of free radical in the assay system) of EEAN was found to be $494.50 \pm 2.62 \mu \mathrm{g} / \mathrm{ml}$.

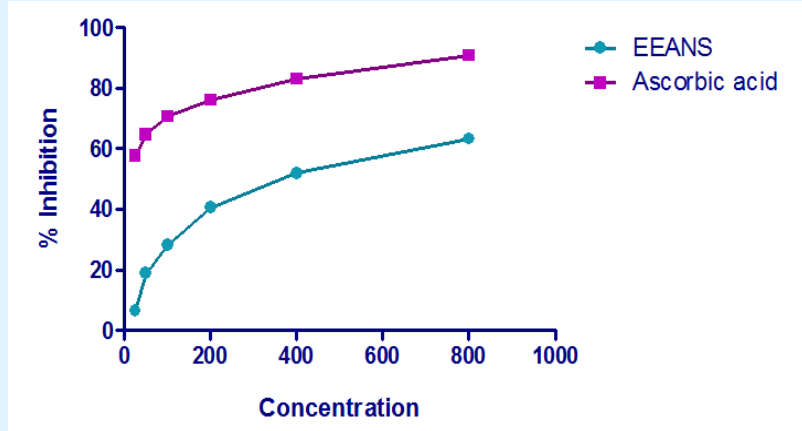

Figure 1: Free radical scavenging activity of EEAN by DPPH method.

\section{Hydroxyl Radical Scavenging Assay}

Figure 2 shows the antioxidant capacity of EEAN by scavenging the hydroxyl radical. The antioxidant activity was increased from $6.35 \pm 0.32 \%$ at $25 \mu \mathrm{g} / \mathrm{ml}$ to $60.47 \pm$ 0.456 at $800 \mu \mathrm{g} / \mathrm{ml}$ concentration. The $\mathrm{IC}_{50}$ value of the extract was found to be $579.57 \pm 1.85 \mu \mathrm{g}$.

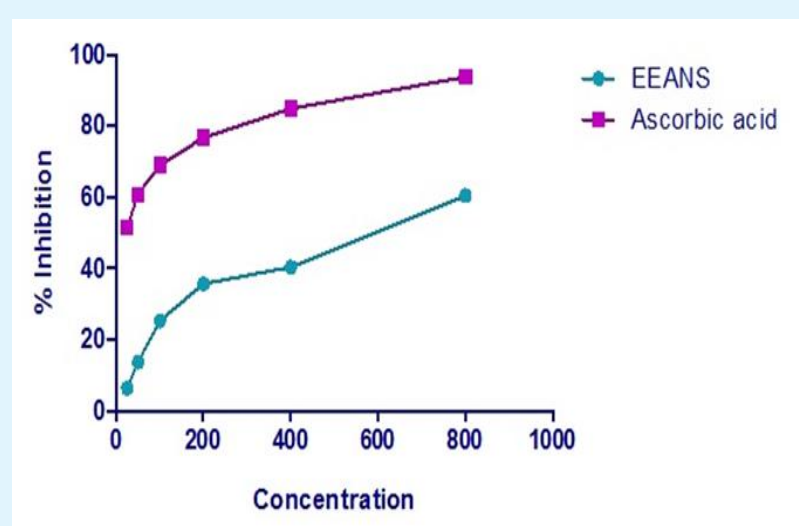

Figure 2: Free radical scavenging activity by Hydroxyl radical scavenging method.

\section{Nitric Oxide Scavenging Assay}

Figure 3 shows the appreciable antioxidant activity by scavenging the nitric oxide. The value of the antioxidant assay increased from $7.62 \pm 0.24 \%$ at $25 \mu \mathrm{g} / \mathrm{ml}$ to $63.64 \pm$ $0.10 \%$ at $800 \mu \mathrm{g} / \mathrm{ml}$. The $\mathrm{IC}_{50}$ value was found to be 469.56 $\pm 2.16 \mu \mathrm{g}$.

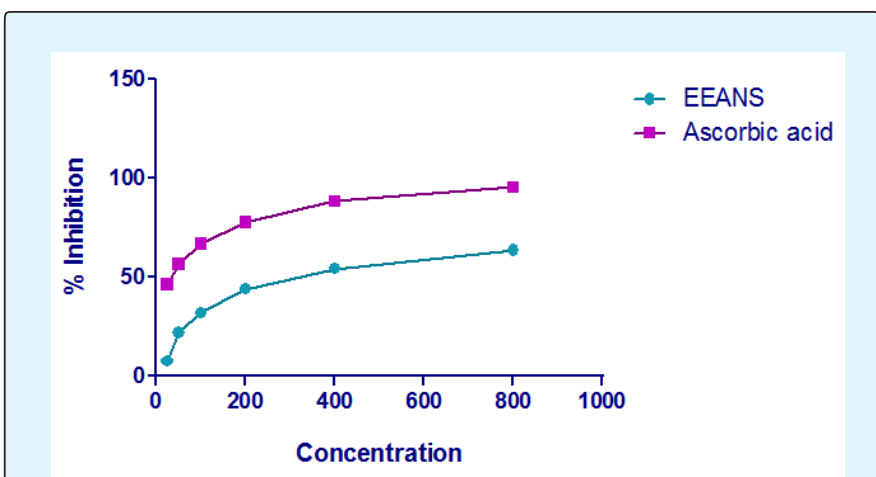

Figure 3: Nitric Oxide scavenging activity of EEAN.

\section{Total Reducing Ability}

The result shows that the EEAN possesses significant antioxidant properties which could react with free radicals to stabilize and terminate radical chain reactions. The reducing powers of ethanolic root extract of Aconitum napellus Linn. was 0.284 at $125 \mu \mathrm{g} / \mathrm{ml}$ and increased to 0.923 at $500 \mu \mathrm{g} / \mathrm{ml}$ (Figure 4). The standard drug ascorbic acid shows the reducing power 1.63 at $500 \mu \mathrm{g} / \mathrm{ml}$.

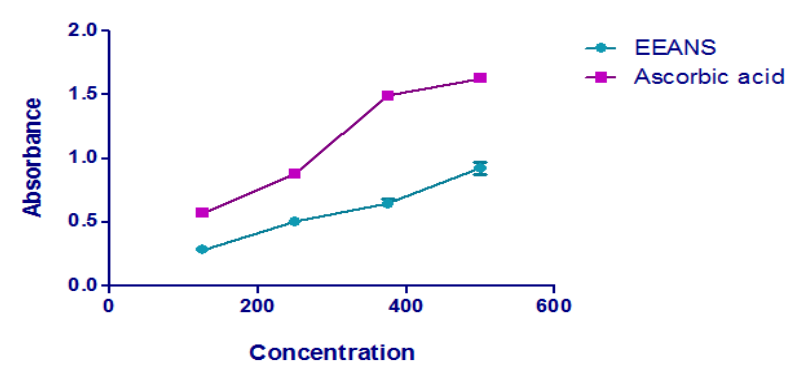

Figure 4: Determination of Reducing Power of EEAN.

\section{HPTLC analysis}

The chromatographic profiles of the ethanolic root extract of EEAN were performed on silica gel 60F254. The plate using Diethylamine: Ethylacetate: Toluene (10:20:70) as mobile phase was given in Figure 5. Thin layer chromatography profiles revealed 2 distinct spots under UV $(254 \mathrm{~nm})$. This was again confirmed in HPTLC 
chromatogram (Figure 6) where The $R f$ values and the peak area percentage were observed and given in Table 1.

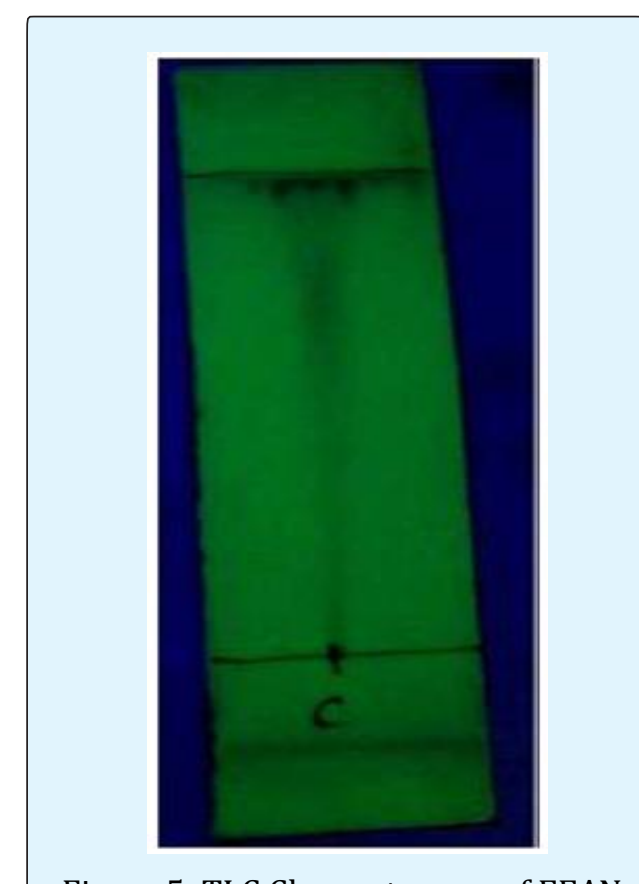

Figure 5: TLC Chromatogram of EEAN.

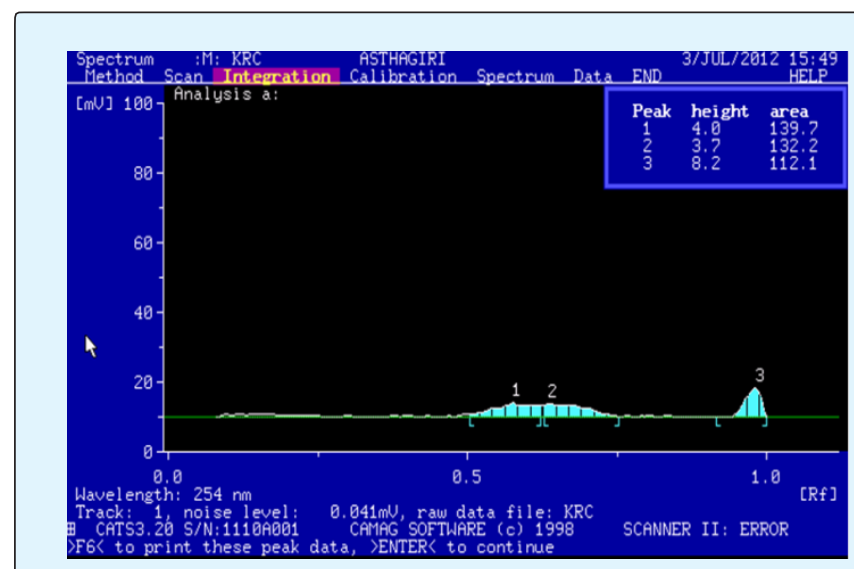

Figure 6: HPTLC Chromatogram of EEAN.

\begin{tabular}{|c|c|c|c|c|}
\hline Peak & Rf & Lambda max & Height & Area in $\mathbf{~ m V}$ \\
\hline 3 & 1 & 254 & 8.2 & 112.1 \\
\hline
\end{tabular}

Table 1: HPTLC fingerprint of ethanolic extract of EEAN.

\section{Discussion}

Three different radical scavenging assay has been performed to find the antioxidant potential of EEAN.

Antioxidants are responsible for the reduction of DPPH into its hydrazine form and make it into a diamagnetic molecule by electron donation. $\lambda_{\max }$ of DPPH, a stable free radical is at $517 \mathrm{~nm}$. Diminution in absorption at $517 \mathrm{~nm}$ is one of the distinctive indication of DPPH reduction. In this study, the result was determined as a ratio between the percentage of absorbance decline of DPPH radical in existence of EEAN to the absorbance of DPPH radical alone at $517 \mathrm{~nm}$. According to this study, it may be assumed that DPPH gets reduced to its resultant hydrazine form by EEAN. This reduction clues to the color conversion of DPPH from purple to yellow based on a number of electrons taken up [12, 34-35].

Various types of ROS viz. hydroxyl radical and singlet oxygen are produced in the biochemical system due to the reaction between $\mathrm{H}_{2} \mathrm{O}_{2}$ and superoxide radical. They are the master regulator for numerous life-threading diseases like cytotoxicity, aging by modifying or damaging DNA, and carcinogenesis etc. From this analysis, it may be hypothesized that EEAN may capable to quench hydroxyl radical and scavenge ROS, and can check the detrimental effects of ROS at the cellular level.

Nitric oxide is lipophilic in nature. At biological $\mathrm{pH}$, it produces nitrogen dioxide once it reacts with oxygen. The various physiological roles of nitric oxide are governing signal transmission, inflammatory response, and vasodilation [36]. Scavengers of nitric oxide race with oxygen and hinder the conversion of nitric oxide [37]. Our study reveals that EEAN may act as an antioxidant by obstructing the conversion of nitric oxide.

An examination of reducing power can explore the antioxidant profile of polyphenols. The reducing reaction is directed by the existence of reductones, which display antioxidant property by providing hydrogen atom and collapsing free radical chain reaction.

Depending on the reducing power capacity of antioxidants present in EEAN, the ferric ion is gets reduced into a ferrous ion, which determined by color change [38].

Appropriate documentation and quality control of the presence of active constituent can be done by HPTLC fingerprint analysis. Different chromatographic record (like HPLC, HPTLC, LC-MS/MS) can offer several elementary pieces of information like chemical compounds for identification, isolation, purification, metabolic safety, permeability, and pharmacokinetic profile of a particular plant species in the animal model also $[39,40]$.

In HPTLC due to solvent, we observe first 2 peaks. Peak 3 confirms the presence of active principles in the extract. Although the further experiment is mandatory to identify and categorize those compounds. This HPTLC fingerprint 
analysis profile of Aconitum napellus Linn. may be used for quality evaluation and standardization.

In acute toxicity studies, mortality was observed in the groups treated with Aconitum napellus Linn. at the dose of $2000 \mathrm{mg} / \mathrm{kg}$ (Tables $2 \& 3$ ). So, the dose must need to optimize before experiment and treatment.

\begin{tabular}{|c|c|c|c|c|}
\hline Parameters observed & I hr & II hr & III hr & IV hr \\
\hline Piloerection & - & - & - & \\
\hline Edema & - & - & - & \\
\hline Urine stains & - & - & - & \\
\hline Alopecia & - & - & - & \\
\hline Loss of writing Reflex & - & - & - & \multirow{2}{*}{ D } \\
Circling & + & + & + \\
A Nasal sniffing & + & + & + & D \\
\hline Lacrimation & & & & \\
\hline Seizures & & & & \\
\hline Righting reflex & & & & \\
\hline Grip strength & & & & \\
\hline Eye closure at touch & & & & \\
\hline Rearing & & & & \\
\hline Straub tail & & & & \\
\hline
\end{tabular}

+: Presence; -: Absence

Table 2: Acute toxicity dose $2000 \mathrm{mg} / \mathrm{kg}$ (P.0). Initial observation (Day-I).n= Three animals of a single sex.

\begin{tabular}{|c|c|c|c|c|}
\hline $\begin{array}{c}\text { Parameters } \\
\text { observed }\end{array}$ & Day-1 & Day-2 & Day-3 & Day-4 \\
\hline Piloerection & \multirow{14}{*}{$\begin{array}{l}\mathrm{D} \\
\mathrm{E} \\
\mathrm{A} \\
\mathrm{D}\end{array}$} & \multirow{14}{*}{$\begin{array}{l}\mathrm{D} \\
\mathrm{E} \\
\mathrm{A} \\
\mathrm{D}\end{array}$} & \multirow{14}{*}{$\begin{array}{l}\mathrm{D} \\
\mathrm{E} \\
\mathrm{A} \\
\mathrm{D}\end{array}$} & \multirow{14}{*}{$\begin{array}{l}\mathrm{D} \\
\mathrm{E} \\
\mathrm{A} \\
\mathrm{D}\end{array}$} \\
\hline Edema & & & & \\
\hline Urine stains & & & & \\
\hline Alopecia & & & & \\
\hline $\begin{array}{l}\text { Loss of writing } \\
\text { reflex }\end{array}$ & & & & \\
\hline Circling & & & & \\
\hline Nasal sniffing & & & & \\
\hline Lacrimation & & & & \\
\hline Seizures & & & & \\
\hline Righting reflex & & & & \\
\hline Grip strength & & & & \\
\hline $\begin{array}{c}\text { Eye closure at } \\
\text { touch }\end{array}$ & & & & \\
\hline Rearing & & & & \\
\hline Straub tail & & & & \\
\hline
\end{tabular}

Mortality was observed in the groups treated with EEAN at the dose of $2000 \mathrm{mg} / \mathrm{kg}$.

Table 3: Acute toxicity-Daily observation. $\mathrm{n}=$ Three animals of a single sex.

\section{Conclusion}

EEAN showed significant antioxidant profile. This study offers experimental support for the traditional medicinal plants.

To confirm therapeutic effectiveness and quality control of the drug along with its identification, this HPTLC data will serve as the reference standard for scientists engaged. So along with the antioxidant property of this plant, HPTLC fingerprint data of root extract of Aconitum napellus Linn. can be used as diagnostic tool for the correct identification of the plant and also used to estimate genetic variability in their population.

Based on the toxicity study, Aconitum napellus Linn. was found to be toxic at a dose of $2000 \mathrm{mg} / \mathrm{kg}$.

Still, molecular studies of the above-mentioned plant may open up new hope in drug discovery and research.

\section{Conflict of Interest Statement}

The authors declare no conflicts of interest.

\section{Acknowledgment}

Authors are grateful to Asthagiri Herbal Research Foundation and C. L. Baid Metha College of Pharmacy for providing us the laboratory facilities.

\section{References}

1. Sánchez Moreno C, Larrauri JA, Saura-Calixto F (1999) Free radical scavenging capacity of selected red, rose and white wines. Journal of the Science of Food and Agriculture 79(10): 1301-1304.

2. Onkar P, Bangar J, Karodi R (2012) Evaluation of Antioxidant activity of traditional formulation Giloy satva and hydroalcoholic extract of the Curculigo orchioides gaertn. Journal of Applied Pharmaceutical Science 2: 209-213.

3. Navarro MC, Montilla MP, Martín A, Jiménez J, Utrilla MP (1993) Free radical scavenger and antihepatotoxic activity of Rosmarinus tomentosus. Planta Medica 59(4): 312-314.

4. Robak J, Gryglewski RJ (1988) Flavonoids are scavengers of superoxide anions. Biochemical pharmacology 37(5): 837-841.

5. Govindarajan R, Vijayakumar M, Rawat A, Mehrotra S (2003) Free radical scavenging potential of 
Picrorhiza kurrooa Royle ex Benth. Indian J Exp Biol 41: 875-879.

6. Jayaprakasha G, Singh R, Sakariah K (2001) Antioxidant activity of grape seed (Vitis vinifera) extracts on peroxidation models in vitro. Food chemistry 73(3): 285-290.

7. Gorain B, Choudhury H, Kundu A, Sarkar L, Karmakar $S$, et al. (2014) Nanoemulsion strategy for olmesartan medoxomil improves oral absorption and extended antihypertensive activity in hypertensive rats. Colloids and Surfaces B: Biointerfaces 115: 286-294.

8. Babu B, Shylesh B, Padikkala J (2001) Antioxidant and hepatoprotective effect of Acanthus ilicifolius. Fitoterapia 72(3): 272-277.

9. Debnath P, Dey P, Chanda A, Bhakta T (2012) A survey on pineapple and its medicinal value. Scholars Acad J Pharm 1(1): 24-29.

10. Dey P, Debnath P, Bhakta T (2012) Evaluation of Anthelmintic Activity Of Molineria Recurvata Leaf Extracts. Int Res J Pharm App Sci 2(2): 16-20.

11. Dey P, Bhakta T (2012) Evaluation of in-vitro anticoagulant activity of Molineria recurpata leaf extract. J Nat Prod Plant Resour 2(6): 685-688.

12. Karuna D, Dey P, Das S, Kundu A, Bhakta T (2017) In vitro antioxidant activities of root extract of Asparagus racemosus Linn. Journal of Traditional and Complementary Medicine 8(1): 60-65.

13. Dey P, Karuna D, Bhakta T (2014) Medicinal Plants used as Anti-Acne Agents by Tribal and Non-Tribal People of Tripura, India. American Journal of Phytomedicine and Clinical Therapeutics 2(5): 556570.

14. Dey P, Das N, Kumar NR, Subramani C, Bhakta T (2013) Mineral contents of some commonly consumed tribal foods of Tripura, India. International Journal of Pharmacy and Pharmaceutical Sciences 5(1): 388-390.

15. Dey P, Bardalai D, Kumar NR, Subramani C, Mukherjee M, et al. (2012) Ethnomedicinal Knowledge about Various Medicinal Plants Used by the Tribes of Tripura. Research Journal of Pharmacognosy and Phytochemistry 4(6): 297-302.

16. Jeon M, Park J, Dey P, Oh Y, Oh H, et al. (2017) Site-Selective Rhodium (III)-Catalyzed C- $\mathrm{H}$
Amination of 7-Azaindoles with Anthranils: Synthesis and Anticancer Evaluation. Advanced Synthesis \& Catalysis 359(20): 3471-3478.

17. Dey P, Bhakta T (2012) Nanotechnology for the Delivery of Poorly Water Soluble Drugs. The Global Journal of Pharmaceutical Research 1(3): 225-250.

18. Jeong T, Lee SH, Mishra NK, De U, Park J, et al. (2017) Synthesis and Cytotoxic Evaluation of $\mathrm{N}$-Aroylureas through Rhodium (III)-Catalyzed C- $\mathrm{H}$ Functionalization of Indolines with Isocyanates. Advanced Synthesis \& Catalysis 359(13): 2329-2336.

19. Dey P, Das N (2013) Carbon Nanotubes: It's Role In Modern Health Care. Int J Pharm and Pharm Sci 5(4): 9-13.

20. Jeong T, Mishra NK, Dey P, Oh H, Han S, et al. (2017) $\mathrm{C}$ (sp 3)-H amination of 8-methylquinolines with azodicarboxylates under Rh (iii) catalysis: cytotoxic evaluation of quinolin-8-ylmethanamines. Chemical Communications 53(81): 11197-11200.

21. Joshi V, Joshi RP (2013) Some plants used in ayurvedic and homoeopathic medicine. Journal of Pharmacognosy and Phytochemistry 2(1): 269-275.

22. Singhuber J, Zhu M, Prinz S, Kopp B (2009) Aconitum in traditional Chinese medicine-a valuable drug or an unpredictable risk? Journal of ethnopharmacology 126(1): 18-30.

23. Ameri A (1997) Inhibition of rat hippocampal excitability by the Aconitum alkaloid, 1benzoylnapelline, but not by napelline. European journal of pharmacology 335(2): 145-152.

24. Menghani E, Soni M (2012) Antimicrobial efficacy of Cassia tora and Aconitum napellus. Int J Pharm Pharm Sci 4(3): 46-53.

25. Luis J, Valdés F, Martín R, Carmona A, Díaz JG (2006) DPPH radical scavenging activity of two flavonol glycosides from Aconitum napellus sp. lusitanicum. Fitoterapia 77(6): 469-471.

26. Dey P, Mukherjee M, Bhakta T, Ghosh T (2012) Preliminary phytochemical studies of leaf extracts of Molineria Recurvata. J Chem Pharm Res 4(7): 37273730 .

27. Wong SP, Leong LP, Koh JHW (2006) Antioxidant activities of aqueous extracts of selected plants. Food chemistry 99(4): 775-783. 
28. Ramakrishna H, Murthy SS, Divya R, MamathaRani D, Panduranga MG (2012) Hydroxy radical and DPPH scavenging activity of crude protein extract of Leucas linifolia: A folk medicinal plant. Asian J Plant Sci Res 2(1): 30-35.

29. Green LC, Wagner DA, Glogowski J, Skipper PL, Wishnok JS, et al. (1982) Analysis of nitrate, nitrite, and $[15 \mathrm{~N}]$ nitrate in biological fluids. Analytical biochemistry 126(1): 131-138.

30. Ylldırım A, Mavi A, Kara AA (2001) Determination of antioxidant and antimicrobial activities of Rumex crispus L. extracts. Journal of agricultural and food chemistry 49(8): 4083-4089.

31. Jonsson M, Jestoi M, Nathanail AV, Kokkonen UM, Anttila M, et al. (2013) Application of OECD Guideline 423 in assessing the acute oral toxicity of moniliformin. Food and chemical toxicology 53: 2732.

32. Sankhari JM, Jadeja RN, Thounaojam MC, Devkar RV, Ramachandran A (2010) Safety evaluation of Eugenia jambolana seed extract. Asian Pacific Journal of Tropical Medicine 3(12): 982-987.

33. Nana HM, Ngane RN, Kuiate J, Mogtomo LM, Tamokou JD, et al. (2011) Acute and sub-acute toxicity of the methanolic extract of Pteleopsis hylodendron stem bark. Journal of ethnopharmacology 137(1): 70-76.

34. Shirwaikar A, Rajendran K, Kumar CD (2004) In vitro antioxidant studies of Annona squamosa Linn. leaves. Indian J Exp Biol 42: 803-807.
35. Prasad KN, Divakar S, Shivamurthy GR, Aradhya SM (2005) Isolation of a free radical-scavenging antioxidant from water spinach (Ipomoea aquatica Forsk). Journal of the Science of Food and Agriculture 85(9): 1461-1468.

36. Rees D, Palmer R, Moncada S (1989) Role of endothelium-derived nitric oxide in the regulation of blood pressure. Proceedings of the National Academy of Sciences 86(9): 3375-3378.

37. Marcocci L, Maguire JJ, Droylefaix MT, Packer L (1994) The nitric oxide-scavenging properties of Ginkgo biloba extract EGb 761. Biochem Biophys Res Commun 201(2): 748-755.

38. Sravani T, Paarakh PM (2012) Antioxidant activity of Hedychium spicatum Buch.-Ham. rhizomes. Indian J Nat Prod Resour 3(3): 354-358.

39. Rammohan B, Samit K, Chinmoy D, Saha A, Kundu A, et al. (2016) Human cytochrome P450 enzyme modulation by Gymnema sylvestre: a predictive safety evaluation by LC-MS/MS. Pharmacognosy magazine 12(4): S389-S394.

40. Bera R, Kundu A, Sen T, Adhikari D, Karmakar S (2016) In Vitro Metabolic Stability and Permeability of Gymnemagenin and Its In Vivo Pharmacokinetic Correlation in Rats-A Pilot Study. Planta medica 82(06): 544-550. 